\title{
Relationship between PaternalParenting Stylesand Antisocial Behaviours among Adolescents of Geidam Metropolis, Yobe State, North-Eastern Nigeria
}

\author{
Shettima Alhaji Umar ${ }^{1}$ Ma'rof Redzuan ${ }^{2} \&$ Hanina Halimatussadiah binti \\ Hamsan $^{3}$ \\ ${ }^{b}$ Faculty of Human Ecology, University Putra Malaysi ${ }^{a}$ Mai Idris Alooma Polytechnic Geidam, Yobe State, \\ Nigeria $^{l}$
}

\begin{abstract}
The present paper aimed was to study paternalparenting styles and its relationship with antisocial behaviours among adolescents. The research was carried out on the sample of 339 males' adolescents' age between 15 to 18 years of Government Science and Technical College and Government Science Secondary School of Geidam Metropolis area of Yobe State in North Eastern Nigeria. Parental Styles Questionnaire (PAQ) of Buri (1991) was administered on adolescents to rate the behaviours of their parents. While, self-youth report questionnaire of Achenbach (1991) was assessed the adolescents antisocial and externalizing behaviours. The results of the study showed that there is a significant positive relationship between paternal authoritarian and permissive parenting styles with antisocial behaviours. Meanwhile, there is significant negative relationship between paternalauthoritative parenting styles with adolescent's antisocial behaviours among adolescents of Geidam Metropolis. Moreover, one-way ANOVA test revealed that parent's education levels has a greater influenced on adolescent's antisocial behaviours. In conclusion, perceived paternal authoritarian and permissive parenting styles have significant positive relationship with antisocial behaviours while, perceived paternal authoritative parenting styles have negative significant relationship to antisocial behaviours among adolescents of Geidam Metropolis.
\end{abstract}

Keywords: paternal authoritative, authoritarian, permissive parenting styles, antisocial behaviours and adolescents.

\section{INTRODUCTION}

In present contemporary era, there are countless of behaviours that displayed by adolescents and children in Nigeria which make right thinking citizens anxious if our country values have been eroded. It is very common to see adolescents molest, subjugate, depress and oppress one another for his own senseless interest (Ikediashi and Akande, 2015). Presently, the antagonists and aggressive adolescents in the Niger Delta district are coming into an end, then Boko Haram sect which known as western education and ideology is prohibited are on-going with their destructions and killing of innocents lives in the Northern part of the country, specifically the situation was became worst from the North Eastern region which are the extreme area of this study(Okoli and Iortyer, 2014). The meaningless killing going on in that region one may assumed if the sect are intended to kill the entire members of Nigerians specifically the Northerners. All these wicked and senseless behaviours which are opposing to the standard social norms and rules and regulation of the society are majorly committed by the children and adolescents associated with antisocial behaviour as a result of negative parenting socialization (Nwanneka, et al., 2015). Many studies showed that in Nigeria the major influenced of children and adolescents antisocial and other internalizing and externalizing behaviours are caused by parents. Poor parental management, lack of adequate monitoring and supervision, harsh and corporal punishment, low parental control, family socio-economic position, parental deficient formal education, physical and emotional deficit and children maltreatment are only few to mention as effects of parents that led to produced antisocial and aggressive adolescents (Olugbenga, 2015). Moreover, the genesis of children antisocial behaviours in Nigeria are broken home, insufficient economic status and sociocultural influence as well as the lack of parental care. The greatest antisocial behaviour displayed by adolescents are violence, aggression, destructions of public and private properties, killing of innocents lives, examination malpractice, substance use, abortion, drugs abuse, stealing, rape, cultism and disrespect and many more (Olugbenga, 2015). Furthermore, Gana(2014) maintained that in Geidam metropolis area of Yobe State, North-Eastern part of Nigeria the menace of adolescent antisocial behaviours become breeding ground, todays it has become a clear indication that most of the public gathering be it on political, religious or in any types of public gathering, antisocial adolescents use this as avenue to harm others. And all these issues came into existence as a result of poor parental monitoring and supervision, poor 
socioeconomic status, lack of education of parents and lack of efficient smooth running of communication and understanding between the parents and their children. Tremendous studies reached consensus that, the genesis of antisocial behaviours of children and adolescents it was rooted from the nature of their parenting styles (Ary, Duncan, Biglan, Metzler, Noell and Smolkowski, 1999). Parental monitoring and supervision, parental management towards their children, harsh discipline and corporal punishment, lack of good rapport and smooth running of interaction and communication it seems to be major important factors in developing antisocial behaviours and other internalizing and externalizing behaviours which can lead them to produce dysfunctional and undesirable outcome (Ary et al., 1999). Parenting socialization are the one of the major instrument to influence children and adolescents in every defined human society. According to Baumrind and Black(1967) different nurture and socialization of parents to their younger one will lead to discrepancy on children behaviours as a result of variation of parental styles. Moreover Baumrind et al., (1967) distinguished three parenting styles based on responsiveness and demandingness toward the socializing of their children and adolescents. She went further to enumerate three types of parenting styles on the basis of these two categories that is authoritative, authoritarian and permissive parenting styles. Authoritative parenting style are those type of parents that display high demandingness and high responsiveness in socializing their children. In such kind parents most of the children became very successful and abide by the societal social norms and values and they will manage to yield a functioning and productive outcome, and this came in to existence as a result of warm and sensitive monitoring and supervision as well as good communication and understanding between the parents and children. However, according to Baumrind (1976) the second type of paternal parenting styles was Authoritarian parents is also a type of parental socialization that have high demandingness and low responsiveness, such type of parents are highly in need their children to conform to they are instruction and command but unfortunately they undermined the right procedure to follow to socialize them to abide by the norm and values of society. The parents are highly over control and over ambitious toward their children but unfortunately they are too harsh, punitive and unforgiving and also given corporal discipline in the name of socialising the children and also there is no smooth running and understanding communication between them (Baumrind, 1976). The third type of parenting styles is permissive parents which display low level demandingness and high level of responsiveness on the affairs of their children. Such type of parents are exhibit through lenience and over indulgence, permissive parents is low in controlling, supervision and monitoring the affairs of their children. They will provide all what is need by their children but they will not supervise the affairs of the children. According to Baumrind theory on parenting styles permissive and authoritarian have conflictual interest in socializing their children and there is a very clear finding acknowledged that both this two types of parenting styles are major determinant of children and adolescents antisocial behaviours(Dwairy, Achoui, Farah and Fayad, 2006). Moreover Hirschi (1969) and Oetting, Donnermeyer and Deffenbacher (1998) postulated that parenting attachment and socialization have a vital role to play to determine the children behaviours. The theory of social bonding of Hirschi (1969) and that of primary socialization theory of Oetting et al., (1998) asserted that antisocial behaviours and other internalizing and externalizing behaviours of children and adolescents is a product of their primary giver that is parents. Family have all the necessary tendency to socialise children to become conform or deviate from the norms and values is depending on the nature of parents that one is being socialized to. Based on the literature findings above on the relationship between perceived paternal parenting styles and antisocial behaviours among adolescents and children the theories of social bonding of Hirschi and parenting styles of Baumrind should be in the right position to explain the variables of this research. This is because, Most of the antisocial behaviours of children are caused by parental harsh and corporal punishment, inefficient monitoring and supervision, parental physical and emotional neglect, low parental control and over control which are the same with the authoritarian and permissive parenting styles as postulated by Baumrind (1967). Moreover, social bonding theory of Hirschi (1969) andOetting, Donnermeyer, and Deffenbacher, (1998) asserted that antisocial behaviours of children was came into existence as a result of poor attachment and socialization by their primary care giver that is parents. This is because family is the entry point and gate keeper of children behaviours and they are negative or positive socialization has a wider complication to children outcome.

\section{METHODOLOGY}

The population of this study was 1556 adolescent of two Secondary schools of Geidam local government area of Yobe state.Moreover, simple random sampling method from the probability sampling type was employed in present study in selection of the respondents, also Cochran (1977) formula was used utilised in selection of 339 respondents out of the entire population of this study from the natural environment of above mentioned schools. This is because simple random sampling give the same and equal chance to entire respondents who fulfilled the inclusive criteria. The inclusive criteria of this study are male adolescent's age 15 to 18 years who live with his biological father. The respondents are males due to the fact that most of the schools children are males. Self-administered questionnaires was presented to the respondents to collect the 
data. While, were briefly explained the main cardinal objective of the study and assured them that the confidentiality of the respondents cannot be reveal in all means. Meanwhile, the collected data of this research was analysed and processed by the used of Statistical Package for Social Science IBM-SPSS version 22.Perceived Paternal parenting styles was measured using parental authority questionnaire (PAQ: Buri 1991). This instrument is very reliable in measurement and it consist of 30 items and this items divided into 3 different subscales and each of the scales contained 10 items, the subscales are authoritarian, authoritative and permissive parental authority questionnaires. This subscale was assessed the adolescent's relationship with their parents. Parental Authority Questionnaire $(\mathrm{PAQ})$ is rated by five likert scale ranging from $1=$ strongly disagree, $2=$ disagree, $3=$ neither agree nor disagree, $4=$ agree and $5=$ strongly agree. While, the independent variable was measured on self-youth report questionnaire by Achenbach (1991) were employed toassessthe adolescents antisocial and externalizing behaviours toward they are interactions with their parents. This instrument consist of three likert scale and have 30 item ranging from $1=$ untrue, $2=$ somewhat true and $3=$ very true or often true

\section{RESULT AND FINDING}

The main purpose of this research was to determine the relationship of independent variables of perceived paternal parenting style (authoritative, authoritarian and permissive) and the dependent variable of adolescent's antisocial behaviours. Hence, Pearson correlation analysis were utilised to determine the relationship between perceived paternal parenting styles and outcome variable of antisocial behaviours among adolescents of Geidam metropolis. Moreover, one-way ANOVA was conductedto compare the difference between respondents' parent's education levels on adolescent's antisocial behaviours. Therefore, Table 1.01 below shows the correlation matric of the entire variables.

Table 1.01: Correlation Analysis of the Study

\begin{tabular}{|ll|r|r|r|r|}
\hline & YSREB_M & Autive_M & Autarian_M & Perm_M \\
\hline YSREB_M & Pearson Correlation & 1 & $.640^{* *}$ & $.658^{* *}$ & $.672^{* * *}$ \\
& Sig. (2-tailed) & & .000 & .000 & .000 \\
& $\mathrm{~N}$ & 339 & 339 & 339 & 339 \\
\hline Autive_M & Pearson Correlation & $.640^{* * *}$ & 1 & $.652^{* *}$ & $.735^{* *}$ \\
& Sig. (2-tailed) & .000 & & .000 & .000 \\
& $\mathrm{~N}$ & 339 & 339 & 339 & 339 \\
\hline Autarian_M & Pearson Correlation & $.658^{* * *}$ & $.652^{* * *}$ & 1 & $.760^{* * *}$ \\
& Sig. (2-tailed) & .000 & .000 & .000 \\
& $\mathrm{~N}$ & 339 & 339 & 339 & 339 \\
\hline Perm_M & Pearson Correlation & $.672^{* * *}$ & $.735^{* * *}$ & $.760^{* * *}$ & 1 \\
& Sig. (2-tailed) & .000 & .000 & .000 & 339 \\
& $\mathrm{~N}$ & 339 & 339 & 339 \\
\hline
\end{tabular}

Table 1.02: Correlation Matrix of independent variables and Antisocial Behaviours

\begin{tabular}{lcccc}
\hline \hline Variables & $\mathbf{Y}$ & $\square_{\mathbf{1}}$ & $\square_{\mathbf{2}}$ & $\square_{\mathbf{3}}$ \\
\hline Y (Antisocial Behaviours) & 1 & & & \\
$\square_{\mathbf{1}}$ (Authoritative Paternal Parenting Style) & $-.640^{* *}$ & 1 & & \\
$\square_{\mathbf{2}}$ (Authoritarian Paternal Parenting Style) & $.658^{* *}$ & $.652^{* *}$ & 1 & $.75^{* *}$ \\
$\square_{\mathbf{3}}$ (Permissive Paternal Parenting Style) & $.672^{* *}$ & $.760^{* *}$ & 1 \\
\hline \hline
\end{tabular}

**. Correlation is significant at the 0.01 level (2-tailed).

*. Correlation is significant at the 0.05 level (2-tailed).

The Pearson correlational analysis was carried out to determine the relationship between perceived paternal authoritative parenting style and antisocial behaviours among adolescents. As indicated in Table 1.01 above, there is a high negative significant relationship between perceived paternal authoritative parenting style and antisocial behaviours $(\mathrm{r}=-.640, p<.01)$. The finding of this result showed that there is a significant but negative relationship between perceived paternal authoritative parenting styles and adolescents antisocial behaviours in the study area. This study finding is in agreement with the study of Moitra and Mukherjee (2010) which found that paternal parenting styles have significant but high negative relationship with internalizing and externalizing behaviours of children and adolescents. Similarly, in another development Akhter, Hanif, Tariq 
and Atta (2011); Yudanagara Bani and Bacan Hacantya (2014) revealed that, paternal parenting styles which characterised by high demandingness and responsiveness in socializing their children and adolescents have negative relationship with antisocial behaviours among adolescents. Many study are in consistent that higher the level of authoritative maternal and paternal parenting style and the lower the level of antisocial behaviours among adolescents will be because of the positive socialization of children which will lead to yield a required and functioning outcome. Furthermore, Pearson correlation analysis of this study was in the same Table indicated that there is significant positive relationship between paternal authoritarian parenting styles and antisocial behaviours $(\mathrm{r}=.658, p<.01)$. The finding of this result is in consistent with Gómez-Ortiz, Romera and Ortega-Ruiz (2016) which indicated that paternal authoritarian parenting style which have high demandingness and low responsiveness in socializing their children and adolescents have significant positive relationship with antisocial behaviours. Meanwhile, Mckee et al., (2008) and Batool et al., (2013) revealed that paternal authoritarian parenting styles which characterised by hash and corporal punishment, over controlling and strike command in socializing children and adolescents have significant positive relationship with internalizing and externalizing behaviours among adolescents. Moreover, in support of the result of this study Hoeve et al., (2011) found that neglectful and authoritarian parenting style of father and mother have high significant positive relationship with antisocial behaviours. Hence, the Pearson correlation analysis of this study in the above Table indicated that, there is a high significant relationship between paternal permissive parenting styles and antisocial behaviours among adolescents $(\mathrm{r}=.672, p<.01)$. The finding of this result is in line with the studies of Alizadeh et al., (2011);Akhter et al., (2011); Moitra and Mukherjee (2010) which indicated that paternal parenting styles that characterised by indulgent, lenience and insufficient monitoring and supervision have positive significant relationship with antisocial, internalizing and externalizing behaviours among adolescents. Generally, in support of present study Querido, Warner and Eyberg (2002) which maintained that adolescent's antisocial behaviours have a negative relationship with authoritative parents and have positive correlational relationship with authoritarian and permissive parents. similarly, Noreen Akhter, Rubina Hanif, Naeem Tariq and Mohsin Atta (2011) which revealed that there is positive relationship between authoritarian and permissive parenting styles with adolescents internalizing and externalizing and other antisocial behaviours, while authoritative parenting styles found negative relationship with adolescents antisocial behaviours. However, in order to compare the difference amongst respondents' parent's education levels on their antisocial behaviours, a One-Way ANOVA analysis was carried out. Hence, Table 1.03 presented below showed the one-way ANOVA assessment of parent's education levels on antisocial and externalizing behaviours among adolescents.

Table 1.03: ANOVA Test of Education Level on Antisocial Behaviours

\begin{tabular}{|c|c|c|c|c|c|c|c|}
\hline \multicolumn{2}{|l|}{ Variable } & $N$ & Mean & SD & $D f$ & $\mathbf{F}$ & $p$ \\
\hline Education Level & & & & & 4 & 4.767 & .001 \\
\hline Informal Educatio & & 94 & 2.78 & .55 & 334 & & \\
\hline $\begin{array}{l}\text { Primary } \\
\text { Certificate }\end{array}$ & School & 47 & 2.76 & .52 & & & \\
\hline $\begin{array}{l}\text { Secondary } \\
\text { Certificate }\end{array}$ & School & 46 & 2.72 & .53 & & & \\
\hline Diploma & & 67 & 2.69 & .48 & & & \\
\hline Degree and above & & 85 & 2.47 & .46 & & & \\
\hline
\end{tabular}

The ANOVA result in Table 1.03 above indicated that there was a significant difference between the respondents parents education level on antisocial behaviours, $\mathrm{F}_{(4,388)}=4.767, p<.05$. Moreover, the result also displayed there is a significant difference between informal education and degree and above, and significant difference primary school certificate and degree and above. Though, ANOVA test also indicated no more significant difference between secondary school certificate, diploma or equivalent and degree and above in the level of adolescents antisocial behaviours. This undoubtedly showed that, the respondents who's their parents did not obtained formal education have higher externalizing and antisocial behaviours as compared to those adolescents with literate parents. The result however showed no significant difference between secondary school certificate, diploma and degree and above but, there is insignificant Mean differences across the education levels. This indicated that, the respondent's level of antisocial behaviours were dropping in the ascending order of their parent's education status. That is to say, the higher the respondent's parents education level, the lower the level of antisocial and externalizing behaviours among the adolescents of Geidam Metropolis.

The result of this study is in line with Patterson, DeBaryshe and Ramsey (1990); Ekpo and Ajake (2013) whichrevealed that, academic knowledge andparent's level of education have a very impotence role in determining adolescent's outcome. Parents with higher education level were nurtured and socialized the children and adolescents authoritatively to become a law abiding individual in order to produce desired outcome. 
Similarly, Dollard and Miller (1939); Batool Syeda Shahida (2013) found that literate and educated parents which characterised by high warm and standard nurturing in socializing the children and adolescents have inverse relationship with antisocial behaviours. Furthermore previous studies showed that, most of the authoritarians and permissive parenting styles which characterised by high demandingness and low responsiveness that is to say over controlling and under controlling, inefficient monitoring and supervision to the affairs of their children and adolescents have significant positive relationship with antisocial behaviours (Alizadeh et al., 2011; Akhter et al., 2011; Moitra and Mukherjee, 2010). Meanwhile, ironically people said that a hungry man is an angry man, many of the parents that used to socialised their younger onein authoritarian styles as a result of deficient of education as well as low economic status which will encouraging them to behave in such a way and eventually led the adolescents to engage in antisocial behaviours(Patterson, DeBaryshe and Ramsey, 1990).

\section{CONCLUSION ANDRECOMMENDATIONS}

Based on the finding of this study, it is a clear evidence that adolescents antisocial and other deviance behaviours came in to existence as a result of lack of monitoring and supervision, inefficient communication and understanding between parents and their children, over control and under control, harsh and corporal punishment and poor parental discipline which are occurred as a result of poor educational status are some of the causes' of antisocial behaviours among adolescents. The finding of this study concluded that antisocial behaviours of children and adolescents is the product of authoritarian and permissive parenting styles in which the studies is in line with the of (Querido, Warner, and Eyberg, 2002 and of Noreen Akhter, Rubina Hanif, Naeem Tariq and Mohsin Atta, 2011). While authoritative parenting style have a significant negative relationship with antisocial behaviours of adolescents, this type of parents use to socialized adolescents who abide by the norms and values for the smooth running of the society eventually produced functioning and desirable outcome. This finding is also in line with (Baumrind and Black, 1967). Based on the finding, the study recommended some of the panacea to the adolescent's antisocial behaviours. It is recommended to establish parents training in handling the issue of their children and adolescents behaviours. Likewise, the study recommended to parents to engage themselves to acquire formal education so that it will help them to find some occupations which will make them the running the affairs of theirlives. Moreover this research recommended that, the finding identified of this study would assist the parents to prevent their children to engage in antisocial behaviours by modifying their parenting styles in order to produce conform and rules abiding children. Meanwhile, the recognition effects of negative parenting styles can encourage government's bodies to educate parents to socialise their adolescents in authoritative parenting. And the finding of the research also recommended that traditional rulers and religious clerics would propagate and enlighten that, the entry point of adolescent's antisocial behaviours are rooted from the negative parenting styles, it is more importance to parents to adopt authoritative parenting styles. By doing this, it is the hope of this research that children and adolescents antisocial, aggressive and other externalizing and internalizing behaviours would be minimal while the respects and dignities to which Geidam Metropolis area of Yobe State and society at large will be reinstated in all her ramifications.

\section{REFERENCE}

[1] Achenbach, T.M. (1991). Child behaviour check-list 14-18 Burlington. University of Vermont.

[2] Ary, D.V., T.E. Duncan, A. Bigian, C.W. Metzler, J.W. Noell and K. Smolkowsky, (1999). Developmentof adolescent problem behaviours. Journal of Abnormal Child Psychol., 27: 141-150I.

[3] Akhter, N., Hanif, R., Tariq, N., \& Atta, M. (2011). Parenting styles as predictors of externalizing and internalizing behavior problems among children. Pakistan Journal of Psychological Research, 26(1), 23-41.

[4] Alizadeh, S., Talib, M. B. A., Abdullah, R., \& Mansor, M. (2011). Relationship between parenting style and children's behavior problems. Asian Social Science, 7(12), 195.

[5] Ary, D. V., Duncan, T. E., Biglan, A., Metzler, C. W., Noell, J. W., \& Smolkowski, K. (1999). Development of adolescent problem behavior. Journal of abnormal child psychology, 27(2), 141-150.

[6] Baumrind, D., \& Black, A. E. (1967). Socialization practices associated with dimensions of competence in preschool boys and girls. Child-development, 38(2), 291- 327.

[7] Buri J. R. (1991). Parental authority questionnaire. Journal of personality Assessment, 57(1),

[8] Batool, S. S. (2013). Lack of adequate parenting: A potential risk factor for aggression among adolescents. Pakistan Journal of Psychological Research, 28(2), 217.

[9] Cumsille, P.N. Darling, B. Flatherty, and M.T. Martinez, (2009). "Heterogeneity and change in the patterning of adolescents' perceptions of the legitimacy parental authority: A latent transition model," Child Development, vol. 80, pp. 418- 432.

[10] Dollard, J., \& Miller, N. E. (1939). The hypothesis suggests that the failure to obtain a desired or expected goal leads to aggressive behavior. Frustration and aggression. 
[11] Dwairy, M., Achoui, M., Farah, A., \& Fayad, M. (2006). Parenting styles in Arab Societies: A first cross regional research study. Journal of Cross-cultural Psychology, 33, 105-123.

[12] Ekpo, T. E., \& Ajake, U. E. (2013). Family socio-economic status and delinquency among senior secondary school students in calabar south, cross river state, Nigeria. American International Journal of Contemporary Research, 3(4), 83-88.

[13] Gana. L.M. (2015). The Effects of Adolescent Substance Abuse on the Socio-Economic Development of Yobe State, Nigeria. Department Of Public Administration Mai Idris Alooma Polytechnic, Geidam, Yobe State, Nigeria. International journal of innovative research and development ISSN $2278-0211$.

[14] Gómez-Ortiz, O., Romera, E. M., \& Ortega-Ruiz, R. (2016). Parenting styles and bullying. The mediating role of parental psychological aggression and physical punishment. Child abuse \& neglect, 51, 132-143.

[15] Hoeve, M., Dubas, J. S., Gerris, J. R., van der Laan, P. H., \& Smeenk, W. (2011). Maternal and paternal parenting styles: Unique and combined links to adolescent and early adult delinquency. Journal of adolescence, 34(5), 813- $\quad 827$.

[16] Hirschi, T. (1969). Causes of delinquency. Berkeley, CA: University of California Press.

[17] Ikediashi, N. N., \& Akande, J. A. (2015). Anti-Social Behaviours among Nigerian

Adolescents. Journal of research and method of education 5 (4) 31-36.

[18] Kruger,N.E.Gouws, and A. Dicker, (2011).The Adolescents: An Educational Perspective. Only Study Guide for GED-201W, Universityof South Africa, Pretoria, South Africa.

[19] Lahey, C. A. van Hulle, K. Keenan et al., (2008) "Temperament and parenting during the first year of life predict future child conduct problems, "Journal of AbnormalChild Psychology, vol. 36, no. 8, pp. 1139-1158.

[20] Moitra, T., \& Mukherjee, I. (2010). Does parenting behaviour impacts delinquency? A comparative study of delinquents and non-delinquents. International Journal of Criminal Justice Sciences, 5(2), 274-285.

[21] McKee, L., Colletti, C., Rakow, A., Jones, D. J., \&Forehand, R. (2008). Parenting and child externalizing behaviors: Are the associations specific or diffuse? Aggression and violent behavior, 13(3), 201-215.

[22] Noreen Akhter, Rubina Hanif, Naeem Tariq, and Mohsin Atta (2011) Parenting Styles as Predictors of Externalizing and Internalizing Behavior Problems among Children. Quaid-i-Azam University1. Pakistan Journal of Psychological Research, 2011, Vol. 26, No. 1, 23-41

[23] Nwanneka N. Ikediashi, Joseph A. \& Akande, (2015). Antisocial behaviours among Nigerian adolescents. Department Of Primary Education Studies AlvanIkoku University of Education Owerri, Imo State. Department of Educational Psychology Fct College of Education Zuba Abuja.Journal of Research \& Method in Education (IOSR-JRME) e-ISSN: 2320-7388,p-ISSN: 2320-737X. PP 31-36 www.iosrjournals.org

[24] Oetting, E.R., Donnermeyer, J.F., \& Deffenbacher, J. (1998). Primary socialization theory: The influence of the community on drug use and deviance. Substance use and misuse. 33 (8) 1629-1665.

[25] Okoli, A. C., \& Iortyer, P. (2014). Terrorism and humanitarian crisis in Nigeria: Insights from Boko Haram insurgency. Global Journal of Human-Social Science, 14(1), 40.

[26] Olugbenga Ojo, (2015). Causes and Prevalence of Antisocial Behaviour among Students with Hearing Impairment in Ibadan, Nigeria. Department of Special Education, University of Ibadan, Ibadan. Journal of Education and Practice ISSN 2222-1735 (Paper) ISSN 2222-288X www.iiste.org

[27] Patterson, G. R., DeBaryshe, B., \& Ramsey, E. (1990). A developmental perspective on antisocial behaviours. American psychologist, 44, 329-335. Reprinted in: Gauvain, M \& Cole, M. (Eds.), 2 ${ }^{\text {nd }}$ Ed. (1993, pp. 263271). NY: Freeman.

[28] Querido, J. G., Warner, T. D., \& Eyberg, S. M. (2002). Parenting styles and child behavior in African American families of preschool children. Journal of Clinical Child Psychology, 31, 272-277.

[29] Wachikwu, T. \& Ibegbunam, J. 0. (2012).Psychosocial factors influencing antisocial behaviour among secondary school students in Obio-Akpor Local Area of Rivers State. International Journal of Educational Development, 2 (1) 104-113.

[30] WHO, "Adolescent health," http://www.who.int/topics/adolescent health/en/Yudanagara, B. B. H. (2014). The Difference of Violence Behavior between Male Adolescent Who Have Authoritative and Non Authoritative Parent. International Proceedings of Economics Development and Research, 78, 6. 